\title{
Hacking through the Gordian Knot: Can facilitating operational mentoring untangle the gender research productivity puzzle in higher education?
}

Chantal Davies and Ruth Healey

School of Law, University of Chester, Chester, UK

Email: chantal.davies@ chester.ac.uk 


\title{
Hacking through the Gordian Knot: Can facilitating operational mentoring untangle the gender research productivity puzzle in higher education?
}

\author{
In spite of a number of drivers for change in the pursuit of gender equality in \\ higher education in the UK and beyond, the gender gap in research activity is still \\ widely recognised across most subject disciplines. Over recent years, mentoring \\ strategies have often been seen as the Alexandrian sword capable of cutting the \\ gender deficit 'Gordian Knot'. However, analysis of current practice and \\ dialogue points to a lack of a consistent approach in addressing and implementing \\ HE policy in this area with many initiatives providing standardised non- \\ evidenced based provision aimed at addressing an alleged confidence deficit and \\ exhausting an already fatigued group of successful senior women. This paper \\ seeks to triangulate existing literature with an analysis of data collected from a \\ funded UK based research project ultimately proposing a five-step institutional \\ mentoring approach aimed at providing some inroads into alleviating the gender \\ deficit in research productivity in the academy.
}

Keywords: gender; research activity; equality; diversity; obstacles; progression

\section{Introduction}

In spite of huge inroads and drivers for change in the pursuit of gender equality in higher education (HE) (in the UK, see inter alia Athena SWAN; public sector equality duty pursuant to the Equality Act 2010 and globally British Council workshop 2012), the puzzle remains unsolved as to why female progression in HE remains stultified at the higher levels of leadership and research activity. Whilst females have numerical dominance at undergraduate level and are rapidly moving towards equality at the lecturer level in the UK (ECU 2015), there has been very slow progression towards representation of women in leadership roles and within the professoriate. This underrepresentation threatens the goal of achieving research excellence and particularly in those areas where the starkest underrepresentation is seen such as within Science, 
Engineering and Technology (SET) (Rees 2001; Blackmore 2014). Equally, women would appear to be underrepresented in the more powerful decision-making committees of Higher Education Institutions (HEIs) (Doherty and Manfredi 2005; Jarboe 2016; ECU 2015).

The gender gap in research activity is widely recognised (e.g. Aiston and Jung 2015; UNESCO 2012; Zie and Shauman 1998; Blake and Lavalle 2000; Kyvik and Teigen 1996; European Commission 2008, 2011; European Science Foundation 2009; Obers 2015; Schucan-Bird 2011). A UNESCO study in 2012 found that men occupy $70 \%$ of research positions globally. In Aiston and Jung's (2015) analysis of the Changing Academic Profession (CAP) survey data across five countries (not including the UK), they found that female academics published less than male colleagues over a 3-year period and this gap in research output was particularly an issue for Asian and Japanese female academics (although less of a gender gap could be seen in the USA).

At the heart of dialogue seeking to solve the gender deficit in research productivity in $\mathrm{HE}$, is debate around the importance of mentoring initiatives in addressing this. Analysis of the literature in this area points to a lack of a consistent approach in addressing and implementing HE policy in this area with many initiatives aimed at addressing an alleged confidence deficit and exhausting an already fatigued group of successful senior women. In particular, implementation of mentoring may more frequently be implemented in a standardised manner based on assumptions around an alleged confidence deficit and without an appropriate evidenced foundation.

This paper seeks to bring together the existing literature in this area with an analysis of data collected from a funded UK based research project undertaken by the 
authors in 2015-16 in a post-1992 university ${ }^{1}$ situated in Northern England. By triangulating existing research with the data from this project, this paper suggests a fivestep institutional approach in relation to the implementation of mentoring within HE aimed at severing the 'Gordian Knot' of gender deficit in research productivity in the academy.

\section{Background context}

The female research productivity deficit must be set against the wider gendered landscape in HE (and particularly for the purposes of this paper within the UK). Across the UK in 2013/14 the majority of academic staff within HE were men (55.4\%) (ECU 2015). Women, however, comprised the majority of academic staff in ten of 23 nonSET subject areas whilst $57.9 \%$ of male academic staff worked in SET subjects. The majority of all professors were men (77.6\%) and this was across all subject areas. However the gap was most notable among full-time professors working in SET subject areas where $81.8 \%$ were male. Furthermore, $76 \%$ of men worked full-time compared with $58.3 \%$ of women.

The position in relation to Vice-Chancellors/Principals was equally concerning with just 20\% of women represented at this most senior level in 2013/14 (ECU 2015). However, in this regard, at least, it would appear that the drivers for change are starting to bear fruit in relation to representation of female institutional leaders. Women now hold $22 \%$ of all Vice-Chancellor roles and this represents a net increase of seven female Vice-Chancellors since 2013 (Jarboe 2016). This competes with the 1 in 3 target by

\footnotetext{
${ }^{1}$ The term Post-1992 university is defined by the Higher Education Funding Council for England as a HEI (usually a previous polytechnic) which has acquired university status as a result of the provisions of the Further and Higher Education Act 1992.
} 
2021 set by Lord Davies in his most recent report in relation to women on Boards (Davies 2015).

Since 2013, HEI's have recognized the need to set goals in relation to leadership diversity. Support for this has been given by the specific measures set by the Higher Education Funding Council for England (HEFCE) in its 2015-2020 Business Plan to encourage greater diversity in governing bodies and senior leadership (Jarboe 2016). In addition the introduction of various diversity and equality awards schemes have been developed (in particular Athena $\mathrm{SWAN}^{2}$ ). The linking of Charter Marks and progress on equality and diversity to grant funding is a major driver. In particular, in 2011, Dame Sally Davies, the Chief Medical Officer, linked the attainment of a Silver Athena SWAN award to being short-listed for National Institute for Health Research funding. Similarly, in 2013 Research Councils UK issued a statement of equality and diversity expectations for applicants of grant funding and in 2015 published diversity monitoring information of grant applicants and recipients for the first time (Jarboe 2016).

In spite of some progress in relation to leadership diversity within HE, the gender gap in relation to research activity in the UK continues (HEFCE 2015; UCU 2013). Just as the gender gap in relation to research activity varies geographically so unsurprisingly we see significant variation across disciplines. Doherty \& Manfredi $(2005,2009)$ note that women's research profiles were less developed than those of

\footnotetext{
${ }^{2}$ Athena SWAN is a charter mark established in 2005 by the UK Equality Challenge Unit. This Charter recognizes and encourages commitment to advancing the careers of women in science, technology, engineering, maths, medicine, arts, humanities, social sciences, business and law in professional and support roles within higher education and research (ECU, 2017).
} 
male academics in their study but that this could be due to a high density of women in the more vocationally orientated departments and faculties where traditionally research activity is less pronounced (such as nursing and teaching). Equally, it is suggested that the gender gap in research activity in SET subjects is often more pronounced as work patterns require monitoring of experiments outside of working hours and for women this increases the challenge of balancing caring responsibilities with erratic working hours (Howe-Walsh and Turnbull 2014). Similarly, Knights and Richards (2003) explored the elevated value attributed by HEI's to the 'hard' quantitative research often dominated by men over the 'softer' qualitative study predominantly populated by female academics.

Whilst the academy has undergone a transformation driven by an emerging consumerism, managerialism and globalisation in the last decade, it is still accepted that research is the most important currency in the prestige economy of HE (see inter alia Aiston and Jung 2015; Morley 2014; Baker 2012; Fitzgerald 2014; Macfarlane 2012). The performance-based culture of HE still emphasises research activity of international quality and standing (Baker 2012). As Morley states 'research performance is implicitly associated with the prestige economy in higher education, and is a pathway to academic seniority and indicator for promotion' $(2014,116)$.

Promotion and reward in HE is still significantly linked into performance indicators and reputation capital that research provides. Morley (2016) laments that in the research economy, women are becoming increasingly side-lined. As long as a gender gap remains in the prestige commodity of HE, and promotion still favours research over other academic activities, then women will continue to suffer in relation 
to academic progression (Doherty and Manfredi 2005; Baker 2012). Therefore, developing an understanding of why women are underrepresented in research across the academy has the potential to assist in a greater appreciation of the leadership gender deficit within HE (Obers 2015).

Globally research assessment exercises within the academy may well provide an indicator as to the research productivity of its participants. The relevant assessment exercise within the UK is the Research Excellence Framework (REF) process. Several studies have looked at the gendered consequences of research assessment processes (e.g. Knights and Richards 2003; Haynes and Fearfull 2008; Brookes, Fenton and Walker 2013). Whilst research assessment processes such as the REF may create the objectivity and transparency that can be beneficial to women, equally the demands of meeting the evaluative requirements may work against female patterns of working and reinforce discriminatory practices (Harley 2003; Fletcher et al. 2007; Barrett and Barrett 2011).

The UK research assessment process (both in relation to the REF and its predecessor the Research Assessment Exercise) has been blighted by accusations of institutional sexism (AUT 2004; Donald 2011). In the HEFCE analysis of the 2001 Research Assessment Exercise (RAE), it was revealed that around 64\% of men but only $46 \%$ of women were submitted. This gender disparity led to a focused attempt to eliminate gender bias in the RAE2008 when allowance was made for those with reduced productivity due to extenuating circumstances including maternity leave. The REF2014 solidified and developed the concept of 'special circumstances' further. 
The HEFCE report (2015) on the REF2014 investigated how disability, age, sex, ethnicity, nationality and early career researcher status related to the selection of staff for inclusion in the REF. As with their previous report in 2009 (HEFCE 2009) the data demonstrated a continued marked difference in relation to selection rates between genders. Whilst the proportion of women selected had increased from the RAE in 2008, analysis still demonstrated that $67 \%$ of men compared with $51 \%$ of women were selected in the 2014 REF. Unsurprisingly, differences of selection rates across Units of Assessment were also observed. Equally unsurprising was the finding that there was a larger selection gender disparity for non-early career researchers (58\%) when compared with early career researchers $(80 \%)$. In addition the selection for female early career researchers was actually higher than for male early career researchers. Staff with fractional contracts were significantly less likely to be selected

The HEFCE statistical findings are supported by a survey focussing on the REF2014 undertaken by UCU (2013). UCU received around 7000 responses (43\% female, 57\% male) from academic staff across 153 HEIs. The data revealed that there were high levels of dissatisfaction regarding the way in which requests for reduced outputs had been handled by individual HEIs. 19\% indicated that they had made a reduced output request with female respondents making requests 2.5 times more than male respondents. The unbalanced impact that workload and performance management demands deriving from the REF had placed on women were noted. Close to $75 \%$ of female respondents considered they were unable to undertake the necessary work to produce REFable outputs without working excessive hours. Over $60 \%$ of respondents (more women than men) felt that pressure to meet expectations in relation to the REF had increased their stress levels. Over a third of those employed on fractional contracts 
indicated that they had undertaken half or more of their work on REF outputs outside of paid working hours.

\section{The 'Gordian Knot'}

In Greek mythology, the Gordian knot was an extremely complicated knot tied by Gordius, the king of Phrygia in Asia Minor. According to tradition, the Greek conqueror Alexander the Great took out his sword and cut through the knot. Thus 'cutting the Gordian knot' has emerged as symbol for solving a complicated problem through audacious action (Encyclopaedia Britannica, 2017).

In this regard, the gender gap in progression and research activity could be viewed as one of the most complex knots for the academy to unravel. In seeking to solve the puzzle, numerous studies have focused on female lack of confidence and belief in academic ability as a fundamental barrier to progression (Asmar 1999; Saunderson 2002; Fletcher et al. 2007; Litzky and Greenhouse 2007; Doherty and Manfredi 2005; Bagihole 1994; Eggins 1997; Harris et al.1998; Obers 2015).

This lack of confidence in their social capital and abilities appears to manifest itself in women having weaker career aspirations than their male colleagues and thus being far less likely to put themselves forward for promotion or engage in competitive activities which will enable career progression (Litzky and Greenhouse 2007; Doherty and Manfredi 2005). As one participant in Ober's study stated, 'women apply for promotion only once they are sure they meet the promotion criteria whereas men tend to take more of a risk' $(2015,1225)$. This links in with the well-established 'imposter phenomenon' whereby women who are objectively of high intellect and capable of high levels of achievement internalise feelings that they are an imposter and are not really as capable as others may believe them to be (Imes and Clance 1984; Jostl et al. 2012; 
Howe-Walsh and Turnbull 2014). The consequent fear of being found out or failure thus inhibits women from progressing. In contrast, men would appear to be confident in their abilities and thus feel more able to engage in competitive progressive activities (Doherty and Manfredi 2005).

It has been argued that this lack of professional self-esteem, which may well constrain women from leadership progression and/or pursuing research careers, may mean that they are far more dependent on support in order to progress than their male counterparts (Reskin 1978). This may also explain why lack of collaboration has a significant negative impact on female (but not male) research productivity (Kyvik et al. 1996). Self-esteem as an enabler to facilitate the networking activities necessary for successful research productivity is also notable (Obers 2015, 1224).

Nevertheless, we must be cautious of placing excessive focus on this supposed confidence deficit. Morley (2006) warns against fixating on female lack of confidence as an explanation for the gender gap in the academy. It may be facetious to problematize women in this way in terms of the productivity puzzle. Rather, Morley (2006) argues that lack of confidence is a product of the masculine constructed space that works to disempower women so that they feel less able than they are. Thus it is no surprise that supportive communities in which colleagues feel valued has been found to improve levels of self-esteem (Obers 2015).

Consequently, lack of self-esteem can be closely linked to the systemic undervaluing of female work in the academy. Arguably as women progress into more senior positions and roles that have traditionally been male dominated, so these roles 
and disciplines become devalued (Doherty and Manfredi 2005; Morley 2006).

Debatably therefore, if women feel their work is undervalued at an institutional level then this is an additional factor that they will internalise and will impact upon the confidence to seek progression.

The centrality of the 'self-esteem' hypothesis to the academy gender gap debate has resulted in a corresponding focus on what many believe to be the 'Alexandrian solution' to the confidence deficit i.e. mentoring. Studies have shown that the presence or absence of effective mentoring can be closely correlated to female progression within HE just as a lack of effective mentors can act to further marginalise women (Aiston and Jung 2015; O’Leary and Mitchell 1990). Thus, the presence of effective mentoring can be a significant factor in increasing research productivity and progression (Gardiner et al. 2007; Fletcher 2007; Chesterman 2009; Eliasson, Berggren and Bondestam 2000; Schulze 2010; Obers 2015; Joiner et al. 2004; Pyke 2013; Thanacoody et al. 2006).

Nevertheless, mentoring is contentious and complex and as such should not be pursued as a simplistic means of 'fixing the women' (Morley 2012; Schiebinger 1999). At its best it can work as a redistribution of feminist knowledge and social capital but at its worst it can seek to assimilate women into dominant masculine structures (Morley 2012; McKeen and Bujaki 2007). As Blackmore states 'Academics are more likely to reengage with leadership if mentoring is not merely about learning and complying with, but perhaps changing the rules of the game' $(2014,95)$.

Equally contentious is the impact that mentoring can have on the 'mentors'. Salzman (1996) suggests that senior women are unwilling to put themselves forward as 
mentors as they do not feel they are adequately rewarded for such activity. As Morley explains, mentoring involves 'substantial emotional labour' and may also have the consequence of 'killing the king/queen - the process by which the mentee extracts knowledge, networks and capital from the mentor and then eliminates or displaces him/her' $(2012,125)$. Thus it may be that mentoring responsibility acts as an effective productivity penalty on successful women who are expected to give time that could be used to further develop research and valuable leadership activity in order to develop their mentees. This relies on women being willing to undertake intensive but less valuable pastoral and emotional labour that detracts from their own progression and productivity.

Much of the existing research suggests that same gender mentors are critical in the mentoring process (Obers 2015; Shackleton et al. 2006; Ragins and Scandura 1994). This may be due to the fact that women and men feel more comfortable mentoring their own gender (Ragins 1989; Thanacoody et al. 2006). However, it may also be that mentees feel that the life experience and empathy of women may be more appropriate to the mentoring relationship (Shackleton et al. 2006; Clark 2000; Salzman 1996; Drazga 1998; Obers 2015). Conversely, it is also argued that for effective mentoring to take place women need access to both female and male mentors (Manfredi et al, 1999). Indeed, Thanacoody et al. found that in one of the countries they studied there was a correlation between the success of those women who had been mentored by a male as this had allowed such women access to 'the male power base, networks and rules of the system' $(2006,541)$. Often opposite gender mentoring is through necessity in that an institution lacks sufficient female mentors (Egan 1996). A lack of focus on gendered mentors may also avoid the productivity penalty faced by many female mentors. 
The task therefore for HEI's is to seek to implement effective mentoring initiatives based on firm evidence in order to ensure that measures meet the particular needs of the target group and where appropriate ensure a valid approach to redress historic disadvantage. It is to this evidence base that we now turn.

\section{Methodology}

The overarching research upon which this paper is based provided a multi-layered, qualitative exploration of the influence of gender upon the experiences of academics in relation to research activity and the REF 2014 within an individual research institution.

The research institution is a moderate sized HEI in the North West of England. The number of employed staff within the institution (as of January 2015) was 1,795. Fifty two percent of academic staff were female. This can be benchmarked against the sector average in the UK of $44.6 \%$. The institution has more recently sought to assess research activity based on self-selection for the REF2014. In the 2014 exercise the research institution was fairly unusual across the sector in permitting academic staff to self-select to be considered for submission to the REF. An Equality Impact Analysis carried out by the research institution in relation to the REF in January 2014 compared the equality characteristics of the 215 staff who self-selected and were considered for submission to the REF, and the 151 staff who were eventually selected by the institution for submission. This showed little gender disparity in terms of those who were selected for submission. In contrast, analysis on the equality characteristics of research active staff (i.e. the 215 staff who self-selected for potential submission to REF 2014) compared against the profile of all 527 academic and research staff who were in employment with the research institution on the REF census date found that female staff 
were significantly under-represented amongst research active staff based on those who had self-selected for submission to the REF.

In recent years, the research institution has been committed to supporting the development of excellence and equality in research. This is evidenced by the institutional application to key national/European initiatives in this area. In particular, the institution has been successful in achieving the HR Excellence in Research Award and an institutional Athena Swan Bronze Award. As part of a commitment to these initiatives and more generally in relation to the Public Sector Equality Duty (pursuant to the Equality Act 2010), the research institution thus commissioned the authors to carry out a 12 month funded project looking at barriers to research activity within the institution.

Purposive sampling was used to target academic staff (both male and female) within the research institution. It was not intended that this form of sampling was necessarily proportionate or representative of the group. Research data was collected by means of questionnaires, focus groups and semi-structured interviews.

A ‘Steering Group' was selected from interested and experienced institutional staff members in order to create a thematic structure and strategy for a questionnaire, focus groups and semi-structured interviews. Interaction with relevant key staff also enabled Faculty members to 'buy into' the project and facilitated the purposive sampling of candidates for participation. This Steering Group was made up of 11 academics and support staff from across the institution and was broadly representative in terms of gender, status and age. It acted as a critical friend throughout the research 
process and met on four separate occasions throughout 2015 and 2016 as well as conducting reviews of documentation throughout the project.

The research was conducted in three separate stages over a period of twelve months between 2015-16. In the first stage, a questionnaire was distributed to all academic staff (841 staff members) from across the institution in August 2015. It was considered vital that this research should engage both male and female academics. One of the criticisms of existing studies in this area is that empirical investigation tends to focus just on women and does not engage with the views and attitudes of male academics (Doherty and Manfredi, 2005, 2009). In order to get a representation of the gendered experience of academics in relation to research activity it was considered that both male and female participation was required. The questionnaire provided opportunity for participants to expand upon responses more broadly. This enabled limited qualitative data to be collected from the questionnaire. The questionnaire was utilised to provide a more broad-brush coverage of the central issues from which to drill down further. It also sought to capture limited biographical data of participants in order to ensure analysis of variables could be achieved. One hundred and nineteen responses were received from academic staff which equated to roughly a one in eight return rate. Of the 119 academic staff respondents, $43(36 \%)$ were male and $76(64 \%)$ were female. Age ranged from 25 to 65 and over for both genders. $64 \%$ of the sample were aged between 35 and 54. Twenty-three different job roles were recorded across the sample, ranging from Lecturers to Deans. 56\% of males were either a lecturer or senior lecturer, as were $57 \%$ of females. 
Respondents to the questionnaire were asked if they would be willing to take part in a further in depth semi-structured interview or focus group. From this group, selection for interview and for participation in the focus groups was determined by the research team based on ensuring a representation of participation based on gender, age, discipline and status. Overall, 9 academics were interviewed and 3 focus groups were held (including one with the institutional women's network). The semi-structured interviews were carried out with both male and female staff. The use of semi-structured interviews was considered to provide the privacy that some individuals may have required when discussing sensitive areas. Equally, it enabled issues from the focus groups to be drilled down and also promoted the emancipatory nature of this research.

A system of 'triangulation' was utilised in order to produce a more accurate and objective representation of the purpose of the study. For example, data from the literature review and questionnaires was triangulated with data from the focus groups and semi-structured interviews to attempt to produce comprehensive representation. The co-researcher, research assistant and steering group played the role of a critical friend through participation in a continuous discourse with the data and the principal researcher.

\section{Discussion}

Unsurprisingly one of the core themes that emerged from an analysis of the data in this project was the centrality of mentoring as a solution to the research productivity puzzle within the institution. The researchers have therefore attempted to triangulate these findings with existing studies in this area in order to attempt to advocate a more 
considered and robust approach towards the implementation of mentoring schemes within the academy.

The overarching research was based on an analysis of qualitative data gathered from questionnaires completed by 119 academic staff, 3 focus groups held with 12 academic staff, semi-structured individual interviews with 9 academic staff and 6 REF Managers from across the research institution. Table 1 provides a brief overview of biographical details of participant data used in this paper.

\section{Table 1: Participant pseudonyms and biographical details to be inserted here}

Due to the centrality of the confidence deficit argument in relation to female lack of progression and disparities in research productivity in HE, as above there has clearly been a corresponding focus on the need for mentoring. Indeed, the research institution had already demonstrated its commitment to female focused leadership mentoring with the rolling out of the Aurora Programme (a national programme put in place by the UK based Institute of Leadership and Management). As above, the literature demonstrates that lack of mentors can have a detrimental impact on female progression (Aiston and Jung 2015; O’Leary and Mitchell 1990). Equally, the availability of effective mentors can have a significant impact on gendered productivity and progression (Gardiner et al. 2007; Fletcher 2007; Chesterman 2009; Eliasson, Berggren and Bondestam 2000; Schulze 2010; Obers 2015; Joiner et al. 2004; Pyke 2013; Thanacoody et al. 2006).

Throughout data collection, a central theme that emerged within this research project was the importance of effective mentoring in ensuring gendered progression in 
relation to research activity within HE. Interestingly, participants whilst supporting a common hypothesis that mentoring can have a significant impact on gendered productivity and progression, also illuminated a range of unexpected perspectives explored below. When asked via the questionnaire what support needed to be provided in relation to research activity within the institution, unsurprisingly $43 \%$ of all respondents made reference to the need for mentors. Thirty-two percent of all male respondents made reference to the need for mentors in comparison to $49 \%$ of all female respondents. Thus, whilst mentoring was viewed as an enabler to research activity for both genders, women were slightly more likely to focus on the need for this form of support in their responses. This was drilled down further in the interviews and focus groups.

Mentoring provision across the institution appeared to be inconsistent and sporadic. Some departments had clearly adopted a formalised strategic mentoring scheme geared towards developing research activity:

In relation to mentoring, what we decided in the end to do was not make it a, sort of, hierarchical senior and junior, two person relationship, but divide the department into, sort of, subject areas, and ask those areas to form slightly more informal research groups, and for, sort of, research conversation and mentoring to take place within those groups on a, sort of, peer-to-peer level, so that we weren't, sort of, instituting this sort of, senior junior relationship all the time. (Phil)

Other departments had a more informal mentoring system in place that largely relied on the cooperation and collaboration of colleagues: 
I'll include myself in this but I get staff asking me questions about publications they might be editing ... and so there's mentoring on an informal basis that when they need something they know that they can approach us and ask for it and they know where to go (Paul)

Whilst one could speculate that a consistent approach would be preferred, informal mentoring, using personal networks rather than an imposed formal system, often appeared to work equally well particularly for female respondents who felt able to seek such support out. Some (e.g. Sarah) viewed the finding of useful mentors as the product of luck based on friendship and networking groups whilst others (as can be seen in relation to Maureen below) had a far more focused approach towards seeking out coaching and mentoring:

I'm really lucky that I've got colleagues who are friends who might be a bit further ahead in their career, who might be at the same level, there's a lot of healthy discussion about what to do and when to do it and how...there's about three or four colleagues who I often go and go oh, I can't do anything about this, do you think I should do this? (Sarah)

Throughout my career I've always identified someone as a coach, not a coach, a mentor, sorry, and someone I can trust and have open conversations with and it can be about the personal difficulties ... which was affecting my work and just struggles and/or just, yeah, research and personal development. (Maureen)

Thus, it appeared that whilst informal mentoring was considered effective it did require women to be a part of a peer network that provided them with the opportunities 
to select an appropriate mentor. For those interviewed, being a part of such a network was perceived as fortuitous rather than planned.

Sadly, for other departments within the research institution there seemed to be little evidence of any available mentoring (either formal or informal) in place. All of those participants who made reference to a frustration at the lack of mentoring and support within their particular department were female. The following were two examples of frustration at a lack of mentoring and direction given at a departmental level:

Yeah definitely lack of mentoring, lack of direction really I suppose from managers. (Karen)

I think I have sort of asked for support in the sense of you know, co-supervising students and stuff like that, and the attitude, and I know people are trying to be helpful probably and think this is helpful, but the attitude has sort of been that I'm lacking confidence or that I'm insecure you know, that I should be, 'oh you're well able to do it yourself', sort of thing. (Suzanne)

For Suzanne, she considered that a request for support and mentoring would be linked to a perceived confidence deficit that she felt was viewed as a weakness within her particular discipline. This supports the concerns raised by those such as Morley (2006) who are concerned that a narrative focussing on a confidence deficit only leads to a reproduction of negative perceptions. Thus, not only was mentoring not available to her it was actively viewed by those more senior as inappropriate and irrelevant. 
Even where formal mentoring was made available, this was not always effective. Poor and ineffective mentoring can be counterproductive and actually damage progression particularly where it results in trying to assimilate women into dominant male structures (Morley 2012). Ineffective mentoring had left the following female senior lecturer feeling disappointed and frustrated:

Well anybody who's new to research is paired up with somebody who's supposedly more experienced in the research area but that pairing doesn't necessarily give you anything so I'm paired up with somebody but when I ask him how he manages his, he just says, find the time! ...so there's no mentoring, I don't get mentored. (Georgia)

Thus, for Georgia rather than providing support and guidance the ineffective mentoring provided reinforced her feelings of inadequacy and indeed further discouraged rather than motivated her research activity.

Nevertheless, in spite of some negative experiences, all of those who made reference to the need for mentoring in the focus groups and interviews felt that some such provision was vital to support the progression and development of early career researchers. This was a recurrent theme from both male and female participants:

Well, as a new member of staff, I'm just a lecturer here, but certainly I would like to have a mentor and, you know, guide me through career development, you know, certainly there are many things more to learn in this process. (John)

So in terms of mentoring in terms of research yes, I mean I would really like that, sometimes I look more broadly at my field talking about kind of sociology of physical 
education and the physical education field more broadly and there are so many people that I think oh man, I'd love if that person worked in our department, I'd love to be able to learn off him or her and work together and stuff like that. (Suzanne)

I think if I felt confident and I had someone there just to hold my hand, you know, just to point me in the right direction and say, you know, this is how you go about it, this is what this means, then I would feel far more comfortable about putting the time in. (Jane)

Participants in this regard appeared to have a clear representation of the perfect 'mentor' in their particular discipline. The effective hypothetical mentor for many participants was someone who could 'guide' and 'teach' and 'point in the right direction'. There was a well-defined picture of someone who would provide sympathetic support and altruistically share his or her experience and knowledge to the mentee.

A number of the female participants discussed their own experiences of acting as a mentor for more junior female colleagues. Often this was as a result of external engagement and was beyond the institution whilst others made reference to input into the Aurora Programme that has been rolled out in the research institution. Those involved in mentoring generally felt that it was rewarding both for themselves and those they were paired with:

I'm part of the mentoring scheme for one of the academic organisations that I look at, which meant, you know, so I'm mentoring a woman in her earlier stage of her creating research and I could be mentored by someone else. (Sarah) 
One female senior lecturer who had acted as a mentor for the Aurora Programme did question whether mentoring across roles as part of that initiative was particularly effective:

I was a mentor for the Aurora Programme... and we were given a bit of support from HR which was really useful but then I was kind of mentoring people who came from different backgrounds and I'm not sure necessarily how useful I was. (Gill)

There was a general feeling that the females participating who had reached a fairly senior level within the institution wanted to 'pass on' their expertise and support more junior colleagues:

I think it's important for all genders not just women, for all members of staff who are starting new in the research, they need some mentoring and I've always been very careful to extend that to people because people have been so generous to me in my time. (Gertrude)

I've shared with them my strategies and approaches where I've mapped out where I am and then where you need to be and how you can get there in terms of rungs on the, you know, the different job descriptions, your current job description, the next level. (Maureen)

Thus the characteristics of the 'aspirational hypothetical' mentor described by participants was very much in line with those who, due to their experience, were now in a position to provide mentoring support to more junior colleagues. Once again the idea 
of a supportive guide to navigate the rules of academia was seen as central to effective mentoring.

However, in line with the literature referencing the pressure gendered mentoring schemes can place on successful women (Morley 2012), reference was made for the need to provide those with mentoring responsibilities the remission in order to engage with this. This was a point made by a male rather than female participant:

Certainly [individual professors] get remission against teaching in order to look after the leadership of research, which includes mentoring. (Paul)

Indeed, studies point to a greater willingness of women to give their time to supportive work (whether that be for staff or students) (Ropes-Huilman,2000; Ward and Wolf-Wendel 2004) often without the expectation of remission. Thus, whilst Paul referenced the need for remission (when referring to his male professorial colleagues), Gertrude, a senior female professor, appeared to consider that mentoring was something that should be expected of those at professorial level and that this should be something that is part of a normal workload:

My experience of quite a few professors, not just at [the research institution], in other institutions, by and large many of them are very selfish with their time and they will moan and whinge and say they haven't got time to spare, whereas they really do, because people at the coalface have an immense amount of teaching. (Gertrude)

There was little reference to the importance of targeted gendered mentoring by the participants. As above, studies suggest that women and men feel more comfortable 
being mentored by the same gender (Ragins 1989; Thanacoody et al. 2006). However, other research suggests that effective mentoring for women requires access to both male and female experience (Manfredi et al. 1999; Thanacoody et al. 2006). Most of those making reference to mentoring for female progression in this research appeared to assume that the mentoring would be provided by the same gender. Indeed, this is supported by the Aurora Programme model. However, one senior female professor expressed the view that:

I think mentoring is very, very important but again I think this is less to do with gender than personality. (Gertrude)

Another female professor and manager stated that she had offered to mentor both men and women but only women had taken full advantage of this:

I'm currently mentoring three of the female staff, I've offered the male staff, and we do do it but it's not as often as the females [laughs]. (Maureen)

\section{Findings}

The data collected from the research institution suggested the need for a more nuanced and evidence-based approach towards mentoring. As an enabler to gendered research productivity and progression, any initiatives focussing on developing effective mentoring needs to ensure that the voices of prospective mentors and mentees are listened to at an institutional level. In order for the hypothetical aspirational mentor to become a reality, an appropriate institutional framework and system for evaluation needs to be implemented. 
The literature clearly demonstrates that a lack of mentoring opportunities can have a detrimental impact on female productivity and correspondingly effective mentoring has been shown to have a positive effect on female productivity and progression. The data from the project on which this paper is based demonstrates that a large minority of both male and female participants consider that mentoring is vital for research productivity and progression. During focus groups and interviews, mentoring was referred to by both genders. The experience of mentoring across the institution was inconsistent. Whilst some departments clearly had formal strategic mentoring systems in place others had a more informal approach whilst others had no formal or informal processes. All of those who expressed frustration had experienced a lack of mentoring opportunities and were female. Participants made reference to the need for women to have both male and female mentors and what appeared to be more important was a mentor who had been effectively trained and was interested in providing the support. Studies have pointed to the 'mentor penalty' that some women face whereby support places excessive burden on successful women. Whilst, this was not overt in the data collected it did appear that those senior female academics who had taken on a mentoring role saw this as a moral obligation in addition to their existing duties, whereas male colleagues viewed it as a necessary part of their role but which the institution should provide remission for.

Effective mentoring is needed for all academics geared towards developing research activity. This should be a centrally driven initiative in order to ensure consistency. Targeted female mentoring is not necessarily required and women should have access to both male and female mentors. Remission and value should be attributed 
to mentoring activity and regularly reviewed in order to ensure effective mentoring is taking place.

Whilst targeted mentoring has often been viewed as important in the development of female progression, it is considered that a more formal mentoring and networking system in relation to research activity should be developed within HEIs for both male and female academics. In particular, a more thoughtful and considered approach should be adopted in this regard. Mentoring schemes should thus be developed and reviewed based on the needs of those it is sought to empower. This research has provided an emancipatory platform for academics within a particular institution and an approach is suggested based on this empirical evidence. In particular, inclusive provision in this regard should seek to redress any existing disadvantage to women as well as benefitting early career researchers more generally. Thus the following five-step approach for HEIs in this regard is proposed:

(1) The application of an evidenced-based approach towards the particular needs that a mentoring system seeks to address at an individual institutional level.

(2) The introduction of an institutional formal (rather than ad hoc) mentoring scheme in relation to research activity. This will ensure consistency across disciplines and need not be managed at a departmental level.

(3) Mixed mentoring should be encouraged (although where requested genders may prefer to be mentored by the same gender and this should be accommodated) with focus being placed on the relevance of the expertise and experience of the mentor to the mentee rather than gender.

(4) Appropriate workload remission should be given to mentors and value placed on mentoring activity in any promotion criteria.

(5) Appropriate training should be compulsory and provided to mentors. Equally, regular objective evaluation of mentoring activities and initiatives should be carried out at an institutional level. 


\section{Conclusion}

Furthering understanding of the importance of mentoring in ensuring female progression and productivity in relation to research activity is vital to the institutional, national and international dialogue in this area. Equally, it is important that this dialogue considers effective and evidence based recommendations in order to ensure the implementation of effective mentoring initiatives in order to address the gender deficit in research productivity.

It is clear from the growing body of work in this area that any steps taken in relation to the development of policy and practice aimed at resolving gender disparity in research activity and effective mentoring must be carried out in a subtle and cautious manner. In particular, Singh (2011) when considering steps taken to redress disadvantage within HE warns that action must be carefully driven to avoid 'reinforcing stigma, which may result in negative outcomes'. Indeed, most researchers in this area advocate inclusive practice and policy development, which is directed at all staff. It is with this in mind that the five-step approach advocated in this paper is suggested. The gender deficit in research productivity in HE is indeed a complex knot the untangling of which has long been the subject of debate in the UK and beyond. It may be that the recommendations from this research are at best a blade to sever one strand of an indomitable rope tangle. Nevertheless, if historic and existing disadvantage is to be addressed we must be prepared to continually review and revise embedded often outdated approaches to problems rather than seeking to continually hack away with a blunt and ineffective instrument. 
Acknowledgements: Thank you is given to Anthony Cliffe who provided invaluable support as research assistant on this project and also to the institutional project Steering Group which collectively acted as a critical friend throughout. Equally, acknowledgement is given for the funding and support of the research institution's Research and Knowledge Transfer Office.

\section{References}

Aiston, S., and J. Jung. 2015. "Women academics and research productivity an international comparison." Gender and Education 27(3): 205-220.

Asmar, C. 1999. "Is there a gendered agenda in academia? The research experience of female and male PhD graduates in Australian Universities." Higher Education 38(3): 255-273.

Association of University Teachers. 2004. The unequal academe. London: AUT.

Bagihole, B. 1994. "Being different is a very difficult row to hoe: survival strategies of women academics." In Changing the subject: Women in Higher Education, edited by S. Davies, S., C. Libelska, C., and J. Quinn, 15-28. London: T. and Francis.

Baker, M. 2012. Academic careers and the gender gap. Toronto: UBC Press.

Barrett, L., and P. Barrett. 2011. "Women and academic workloads career slow lane or Cul-de-Sac." Higher Education 61: 141-155.

Blackmore, J. 2014. "Wasting talent Gender and the problematics of academic disenchantment and disengagement with leadership." Higher Education Research \& Development 33(1): 86-99.

Blake, M., and L. La Valle, I. 2000. Who Applies for Research Funding? London: The Welcome Trust.

Broadbent, J. 2010. "The UK Research Assessment Exercise Performance Measurement and Resource Allocation." Australian Accounting Review 20(1): 14-23.

Brookes, C., E. Fenton, and J.Walker. 2013. "Gender and the evaluation of research." Research Policy 43: 990-1001.

Chesterman, C. 2009. "Advancing mentoring through a network for women in higher education across continents and contexts." atn.edu.au, May 2. http://www.atn.edu.au/wexdev/local/docs/advancing_mentoring.pdf

Clark, E. A. 2000. "University administrative careers in family and consumer sciences." Journal of Family and Consumer Sciences 92: 89-94.

Cousin, G. 2009. Researching Learning in Higher Education. Oxford: Routledge.

Davies, M. 2015. Women on boards annual review 2015. London: UK. 
Doherty, L., and S. Manfredi. 2005. Improving Women's representation in senior positions in universities, stage 1 findings. Oxford: Oxford Brookes University.

Doherty, L., and S. Manfredi. 2005. Improving Women's Representation in Senior positions in the HE sector stage 2 findings. Oxford: Oxford Brookes University.

Doherty, L., and S. Manfredi. 2009. "Improving women's representation in senior positions in universities." Employee Relations 32(2): 138-155.

Donald, A. 2011. Levelling the playing field maternity leave, paternity leave and the $R E F$. London: LSE Blog.

Drazga, B. M. 1998. "Mentoring helps break glass ceiling." Denver Business Journal 46: 21-23.

Egan, K. 1996. "Flexible mentoring: adaptations in style for women's ways of knowing." Journal of Business Communications 33(4): 401-425.

Eggins, H. 1997. Women as leaders and managers in Higher Education. Buckingham: Open University Press.

Eliasson, M., H. Berggren, and F. Bondestam. 2000. "Mentoring programmes - a shortcut for women's academic careers?" Higher Education in Europe 25(2): 173-179.

Encyclopaedia Britannica. 2017. "Gordian knot." Encyclopaedia Britannica, https://www.britannica.com/topic/Gordian-knot

Equality Challenge Unit. 2015. "Gender charter marks consultation response." Equality Challenge Unit, http://www.ecu.ac.uk/equality-charter-marks/charter-marksexplained/gender-charter-marks-consultation-response/

Equality Challenge Unit. 2017. "Athena SWAN Charter." Equality Challenge Unit, http://www.ecu.ac.uk/equality-charters/athena-swan/

European Commission. 2008. Mapping the maze: Getting more women to the top in research. Brussels: European Commission.

European Commission. 2011. "Structural change in research institutions: Enhancing excellence, gender equality and efficiency in research and innovation." European Commission, http://ec.europa.eu/research/sciencesociety/document_library/pdf_06/structural- changes-final-report_en.pdf

European Science Foundation. "Structural change in research institutions: Enhancing excellence, gender equality and efficiency in research and innovation." $E S F$, http://www.esf.org/fileadmin/links/CEO/ResearchCareers_60p \%20A4_13Jan.pdf

Fitzgerald, T. 2014. Women leaders in Higher Education: Shattering the Myths. Abingdon: Routledge. 
Fletcher, C., R. Boden., J. Kent., and J. Tinson. 2007. "Performing women: The gendered dimensions of the UK new research economy." Gender Work and Organization 14(5): 433-453.

Gardiner, M., M. Tiggerman., M. Kearns., and K. Marshall. 2007. "Show me the money! An empirical analysis of mentoring outcomes for women in academia." Higher Education Research and Development 26(4): 425-442.

Harley, S. 2003. "Research selectivity and female academics in UK universities: From gentleman's club and barrack yard to smart macho?" Gender and Education 15(4): 377392.

Harris, P., B. Thiele., and J. Currie. 1998. "Success, gender and academic voices, consuming passion or selling the soul?" Gender and Education 10(2): 133-148.

Haynes, K., and A. Fearfull. 2008. "Exploring ourselves: exploiting and resisting gendered identities of women academics in account and management." Pacific Accounting Review 20: 185-204.

Higher Education Funding Council for England. 2015. Equality and diversity in the REF: Final report by EDAP. London: HEFCE.

Higher Education Funding Council for England. 2009. Selection of staff for inclusion in $R A E$ 2008. London: HEFCE.

Howe-Walsh, L., and S. Turnbull, S. 2014. "Barriers to women leaders in academia tales from science and technology." Studies in Higher Education: 1-13.

Imes, S. A., and P. R. Clance. 1984. "Treatment of the impostor phenomenon in high achieving women. In Women working with women, edited by C. Brody, 75-88. New York: Snapfinger Publishing Co.

Jarboe, N. 2016. Women Count: leaders in higher education 2016. London: WomenCount.

Joiner, T., T. Bartram., and T. Garretta. 2004. "The effects of mentoring on perceived career success, commitment and turnover intentions." The Journal of American Academy Business 5(1): 163-170.

Jostl, G., E. Bergsmann., M. Luftenegger., B. Schober., and C. Spiel. 2012. "When will they blow my cover? The impostor phenomenon among Austrian doctoral students." Journal of Psychology 220(2): 109-120.

Knights, D., and W. Richards. 2003. "Sex discrimination in UK academia." Gender Work and Organization 10(2): 213-236.

Kyvik, S., and M. Teigen. 1996. "Child care, research collaboration and gender differences in scientific productivity." Science, Technology \& Human Values 21(1): 5471. 
Litzky, B., and J. Greenhous. 2007. "The relationship between gender and aspirations to senior management." Career Development International 21(7): 637-659.

Macfarlane, B. 2012. Intellectual Leadership in Higher Education: Renewing the role of the University Professor. London: Routledge.

McKeen, C., and M. Bujaki. 2007. "Gender and mentoring." In The handbook of mentoring at work: Theory, research, and practice, edited by B. R. Ragins., and K. Kram, 197-222. Los Angeles: Sage.

Morley, L. 2006. "Hidden transcripts: The micropolitics of gender in Commonwealth universities.” Women's Studies International Forum 29(6): 543-551.

Morley, L. 2012. "The rules of the game women and the leaderist turn in higher education." Gender and Education 25(1): 116-131.

Morley, L. 2014. "Lost leaders women in the global academy." Higher Education Research and Development 33(1): 114-128.

Morley, L. 2016. "Troubling intra-actions gender, neo-liberalism and research in the global academy." Journal of Education Policy 31(1): 28-45.

Oakman, H. 2016. "Females VC's now 29\% of new appointments." University Business, http://universitybusiness.co.uk/Article/breaking-through-the-he-glass-ceiling.

Obers, N. 2015. "Influential structures understanding the role of the head of department in relation to women academics' research careers." Higher Education Research \& Development 34(6): 1220-1232.

O'Leary, V. E., and J. M. Mitchell. 1990. "Women connecting with women: networks and mentors in the United States." In Storming the tower women in the academic world, edited by S. Stiver Lie. and V. E. O'Leary, 58-74. London: Kogan Page.

Pyke, J. 2013. "Women, choice and promotion or why women are still a minority in the professoriate." Journal of Higher Education Policy and Management 35(4): 444-454.

Ragins, B. R. 1989. "Barriers to mentoring: the female manager's dilemma." Human Relations 42: 1-22.

Ragins, B. R., and T. Scandura. 1994. "Diversified mentoring relationships in organisation power perspective." Academy of Management Review 482-521.

Rees, T. 2001). "Mainstreaming gender equality in science in the European Union: The 'ETAN report'." Gender and Education 13(3): 243-260.

Reskin, B. 1978. "Sex differentiation and the social organization of science." In The sociology of Science, edited by J. Gaston, 6-37. San Francisco: Jossey-Bass.

Ropes-Huilman, B. 2000. "Aren't you satisfied yet? Women faculty member's interpretations of their academic work." In What contribute to job satisfaction among 
faculty and staff: New directions for institutional research, edited by L. Hagedorn, 2132. New York: Jossey-Bass.

Salzman, A. 1996. "Woman versus woman." US News and World Report 120: 50-54.

Saunderson, W. 2002. "Women, academia and identity: Constructions of equal opportunities in the 'new managerialism' - a case of lipstick on the Gorilla." Higher Education Quarterly 56(4): 376-406.

Schucan-Bird, K. 2011. "Do women publish fewer journal articles than men, sex differences in publication productivity in the social sciences." British Journal of Sociology and Education 32(6): 921-937.

Schulze, S. 2010. "Mentees' views of a structured mentoring programme at UNISA." South African Journal of Higher Education 24(5): 782-799.

Shackleton, L., S. Riordan., and D. Simonis. 2006. "Gender and the transformation agenda in South African higher education." Women's Studies International Forum 29(6): 572-580.

Singh, G. 2011. Black and minority ethnic (BME) students' participation in higher education: improving retention and success. London: Higher Education Academy.

Thanacoody, R., T. Bartram., M. Barker., and Jacobs, K. 2006. "Career progression among female academics a comparative study of Australia and Mauritius." Women in Management Review 21(7): 536-553.

UCU. 2013. "The research excellence framework UCU survey report." $U C U$, https://www.ucu.org.uk/media/6005/The-Research-Excellence-Framework-REF--UCU-Survey-Report_Oct-13/pdf/REF-survey-report-September-2013.pdf

UNESCO. 2012. "World atlas of gender equality in education." United Nations Educational, Scientific and Cultural Organization, http://www.uis.unesco.org/Education/Documents/unesco-world-atlas-gender-education2012.pdf

University of Chester. 2016. Equality and diversity report 2016. Chester: University of Chester.

Ward, K., and L. Wolf-Wendel. 2004. "Academic motherhood, managing complex roles in research universities." The review of Higher Education 27(2): 233-257.

Zie, Y., and K. Shaunman. 1998. American Sociological Review 63(6): 847-870. 
